\title{
TEMPORAL FREQUENCY OF SOIL TEST INFORMATION EFFECTS ON RETURNS TO POTASSIUM FERTILIZATION IN COTTON PRODUCTION
}

\author{
XAVIER HARMON \\ Department of Agricultural and Resource Economics, The University of Tennessee, Knoxville, Tennessee \\ CHRISTOPHER N. BOYER* \\ Department of Agricultural and Resource Economics, The University of Tennessee, Knoxville, Tennessee \\ DAYTON M. LAMBERT \\ Department of Agricultural and Resource Economics, The University of Tennessee, Knoxville, Tennessee \\ JAMES A. LARSON \\ Department of Agricultural and Resource Economics, The University of Tennessee, Knoxville, Tennessee
}

\begin{abstract}
Little research exists on the optimal temporal frequency between soil tests, given empirical data on potassium $(\mathrm{K})$ carryover and its interaction with cotton yield. We evaluate how decreasing the temporal frequency between obtaining K soil test information affects the net present value (NPV) of cotton production. Monte Carlo simulation was used to determine NPV for cotton production using five soil test schedules ranging from soil testing annually to every fifth year. NPV of returns to $\mathrm{K}$ was maximized at $\$ 7,580 /$ ac. when producers updated soil testing information every 2 years, which was $\$ 2 /$ ac. per year greater than annual soil testing.
\end{abstract}

Keywords. Cotton, dynamic programming, potassium, soil testing, temporal frequency

JEL Classifications. Q10, Q12

\section{Introduction}

Potassium $(\mathrm{K})$ is an important nutrient for upland cotton (Gossypium hirsutum L.) but can be difficult to manage over time (Howard et al., 2001). In the

The authors would like to thank the staff at the West Tennessee Research and Education Center for field research support. The underlying field research was supported by the Tennessee Agricultural Experiment Station, U.S. Department of Agriculture National Institute of Food and Agriculture Hatch project TEN00248, and additional funding was provided by the Potash \& Phosphate Institute Foundation for Agronomic Research and from Cotton Incorporated.

*Corresponding author's e-mail: cboyer3@utk.edu 
late 1980s and early 1990s, there were frequent reports of late-season K deficiencies in the U.S. Cotton Belt (Maples, Thompson, and Varvil, 1988; Mullins, Burmester, and Reeves, 1997), resulting in numerous agronomic studies on cotton response to $\mathrm{K}$ while considering $\mathrm{K}$ levels in the soil that are readily available for plant consumption (soil $\mathrm{K}$ ) from the previous production year (i.e., carryover) (Essington et al., 2002; Howard et al., 1998; Mullins, Schwab, and Burmester, 1999). Findings from these studies triggered extension personnel in several southeastern states to recalibrate $\mathrm{K}$ recommendations to maintain adequate soil $\mathrm{K}$ levels for cotton production and circumvent yield loss because of late-season $\mathrm{K}$ deficiencies. Methods to analyze soil $\mathrm{K}$ levels were developed more than 60 years ago (Mehlich, 1953), but gathering this information using soil tests and applying the information to make $\mathrm{K}$ applications is still a growing practice among cotton producers (Zhou et al., 2015).

If a profit-maximizing producer considers information on soil $\mathrm{K}$ levels before applying a $\mathrm{K}$ rate, the producer's decision framework changes from maximizing net returns in a given year to maximizing the present value of net returns (NPV) over a planning horizon. The switch in the producer's decision framework occurs because application decisions in a given year are based on their application rates from the previous year. Economists developed dynamic programming models to determine nutrient application rates that maximize NPV with nutrient carryover (Fuller, 1965; Heady and Dillon, 1961; Kennedy, 1986; Kennedy et al., 1973; Stauber, Burt, and Linse, 1975). The dynamic programming approach separates the producer's planning horizon into discrete sequential maximization problems, solved by deriving optimality conditions for each period (Bellman, 1957). The single period application rates are conditioned on some knowledge of soil carryover levels prior to planting.

These dynamic models have been adapted to different crops and nutrients (Ackello-Ogutu, Paris, and Williams, 1985; Jomini et al., 2001; Kennedy et al., 1973; Lambert, Lowenberg-DeBoer, and Malzer, 2007; Lanzer and Paris, 1981; Park et al., 2007; Schnitkey, Hopkins, and Tweeten, 1996; Segarra et al., 1989; Watkins, Lu, and Huang, 1998). However, Harper et al. (2012) were first to use a dynamic programming model to determine $\mathrm{K}$ application rates that maximize NPV for upland cotton production. They developed an application for valuing the information from soil testing in cotton production by considering multiple information scenarios in the dynamic programming framework. Harper et al. (2012) used 3 years of data on K soil fertility and cotton lint yields in Tennessee to determine the applied $\mathrm{K}$ rate that maximized NPV when soil $\mathrm{K}$ levels were considered and were not considered in the applied $\mathrm{K}$ rate decision. They found that using the soil K level information annually would increase NPV relative to not considering the soil $\mathrm{K}$ level information over a 5 -year horizon. Additionally, using soil $\mathrm{K}$ carryover knowledge reduced the amount of annual $\mathrm{K}$ that was applied and the soil K carryover levels, which may be helpful for reducing off-site $\mathrm{K}$ leaching. 
A common assumption in the existing dynamic programming literature is that producers annually soil test to update their soil nutrient information. However, gathering information about soil nutrient variability on an annual basis might not increase the NPV (e.g., by reducing fertilizer costs) enough to pay for the cost of gathering soil nutrient information, especially for $\mathrm{K}$ because it is immobile in the soil profile (Walworth, 2011). Currently, state extension recommendations encourage cotton producers to update $\mathrm{K}$ soil test information from annually to every 3 years in the Southeast (Kissel and Sonon, 2011; Mylavarapu, 1997; Savoy and Joines, 2013). These recommendations vary across states because production factors such as cropping intensity, soil type, tillage practices, and weather conditions play an important role in determining the length of time to wait until retesting soil nutrient levels. Nonetheless, the common assumption in the literature of soil testing annually may not be appropriate for all nutrients and crops to maximize NPV.

Lambert et al. (2014) used survey data of cotton producers in 13 southern states to determine the factors affecting the length of time between updating soil test information (temporal frequency) for precision soil sampling. They found that farm size, land ownership, farm location, and farming experience were correlated with the temporal frequency that producers tested soils. Overall, cotton producers who adopted precision soil sampling indicated they retested soils on average every 2.5 years, which is within the range encouraged by Southeast extension agronomists. Moreover, Lambert et al.'s (2014) research indicates that annual soil testing might not be a profit-maximizing frequency.

The objective of this research was to determine the $\mathrm{K}$ application and temporal frequency for obtaining $\mathrm{K}$ soil test information that maximizes NPV to $\mathrm{K}$ in cotton production over a 10 -year planning horizon. Optimal $\mathrm{K}$ rates and NPV were determined ex ante for five soil testing schedules of varying temporal frequencies using Kennedy's (1986) dynamic programming framework. The conceptual modeling of this study extends the literature by considering the temporal frequency of obtaining soil test information in a dynamic programming framework to determine optimal $\mathrm{K}$ rates and expected returns for cotton production. The results can guide producers and extension personnel on optimal $\mathrm{K}$ rates and length of time between soil tests for upland cotton growers.

\section{Empirical Framework}

\subsection{Dynamic Programming Model}

A risk-neutral, profit-maximizing cotton producer chooses an amount of $\mathrm{K}$ to apply $\left(A_{t}\right)$ at the beginning of each production year $(t=1, \ldots, T[T=10])$, conditioned on some knowledge of soil $\mathrm{K}$ carryover $\left(C_{t}\right)$, that maximizes the NPV of returns to K over a planning horizon (Kennedy, 1986; Kennedy et al., 1973). This producer also selects the optimal temporal frequency $j$ of soil testing by 
choosing some discrete number of years between retesting soils. Five soil testing schedules of varying temporal frequency from annually to every fifth year $(j=$ $1, \ldots, 5)$ were considered, where $j$ is the number of years between soil testing.

At the beginning of each production year, the producer had knowledge of current elemental $\mathrm{K}$ prices, an expectation of cotton lint prices at harvest, cotton lint yield response to total available $\mathrm{K}$, and information on soil $\mathrm{K}$ levels from the most recent soil test. For each soil testing schedule, the producer used this a priori knowledge to apply a profit-maximizing amount of K. The optimal temporal frequency was the soil testing schedule that provides the greatest NPV over a 10year planning period. Therefore, the maximized NPV is calculated as follows:

$$
\max _{A_{t, j} \ldots, A_{T, j}} N P V_{j}=\sum_{t=1}^{T} \delta^{t-1} N R_{t, j}
$$

Subject to:

$$
\begin{aligned}
& A_{t, j}, C_{t, j} \geq 0 \\
& C_{t+1, j}=a_{0}+a_{1}\left(A_{t, j}+C_{t, j}\right) \\
& C_{t, j}=\lambda_{j} Q_{t, j}+\left(1-\lambda_{j}\right) Q_{t-1, j} \\
& Q_{0} \text { given, }
\end{aligned}
$$

where $N P V_{j}$ is the sum of discounted net returns (\$/ac.) over $T$ years for a producer following soil testing schedule $j ; A_{t, j}$ is applied $\mathrm{K}$ (lb./ac.); $N R_{t, j}$ is the net returns (\$/ac.) to $\mathrm{K}$ for cotton production; $\delta$ is a discount factor reflecting the time value of money $1 /(1+r)^{t}$, where $r$ is the discount rate; $C_{t, j}$ is the producer's knowledge of carryover $\mathrm{K}\left(\mathrm{lb}\right.$./ac.) in time period $t ; Q_{t, j}$ is the actual carryover $\mathrm{K}$ (lb./ac.) in time period $t$; $C_{t+1, j}$ is the producer's knowledge of carryover $\mathrm{K}(\mathrm{lb} . / \mathrm{ac}$. prior to planting in year $t+1$, which is a function of applied $\mathrm{K}$ and the producer's knowledge of soil $\mathrm{K}$ carryover (i.e., total $\mathrm{K}$ available [lb./ac.]) in year $t ; \lambda_{j}$ is an indicator variable that is equal to 1 in the year a producer updates his or her knowledge of soil $\mathrm{K}$ by soil testing, and 0 otherwise; $a_{0}$ and $a_{1}$ are estimated parameters for the linear carryover function; and $Q_{0}$ is the actual soil $\mathrm{K}$ level before $\mathrm{K}$ is applied in the first production period. Partial budgeting was used to calculate the single period net returns for a risk-neutral profit-maximizing producer, where single period net returns (NR) are the following:

$$
N R_{t, j}=\delta p_{t}^{c} y_{t, j}\left(A_{t, j}+C_{t, j}\right)-p_{t}^{K} A_{t, j}-\lambda_{j} s
$$

where $p_{t}^{c}$ is the producer's expectation of the price of cotton lint at harvest $(\$ / \mathrm{ac}.) ; p_{t}^{K}$ is the producer's observed price of $\mathrm{K}$ at the time of application (\$/ac.); $y_{t, j}$ is cotton lint yield (lb./ac.) in period $t$; and $s$ is the cost of obtaining soil test information prior to applying $\mathrm{K}(\$ / \mathrm{ac}$.), which only occurs in years when the producer tests the soil $\left(\lambda_{j}=1\right)$, or otherwise $s=0$.

Assume the producer conducts a soil test prior to production in the first year; therefore, the producer knows the soil $\mathrm{K}$ level at the beginning of production year 1 and uses this information in selecting an optimal application rate in year 
Table 1. Producer's Knowledge of K Carryover by Temporal Frequency of Soil Testing and Year

\begin{tabular}{|c|c|c|c|c|c|}
\hline \multirow[b]{2}{*}{ Year } & \multicolumn{5}{|c|}{ Temporal Frequency } \\
\hline & $j=1$ & $j=2$ & $j=3$ & $j=4$ & $j=5$ \\
\hline$t=0$ & $Q_{0}$ & $Q_{0}$ & $Q_{0}$ & $Q_{0}$ & $Q_{0}$ \\
\hline$t=1$ & $C_{1,1}^{a}=Q_{1,1}$ & $C_{1,2}=Q_{1,2}$ & $C_{1,3}=Q_{1,3}$ & $C_{1,4}=Q_{1,4}$ & $C_{1,5}=Q_{1,5}$ \\
\hline$t=2$ & $C_{2,1}=Q_{2,1}$ & $C_{2,2}=Q_{1,2}$ & $C_{2,3}=Q_{1,3}$ & $C_{2,4}=Q_{1,4}$ & $C_{2,5}=Q_{1,5}$ \\
\hline$t=3$ & $C_{3,1}=Q_{3,1}$ & $C_{3,2}=Q_{3,2}$ & $C_{3,3}=Q_{1,3}$ & $C_{3,4}=Q_{1,4}$ & $C_{3,5}=Q_{1,5}$ \\
\hline$t=4$ & $C_{4,1}=Q_{4,1}$ & $C_{4,2}=Q_{3,2}$ & $C_{4,3}=Q_{4,3}$ & $C_{4,4}=Q_{1,4}$ & $C_{4,5}=Q_{1,5}$ \\
\hline$t=5$ & $C_{5,1}=Q_{5,1}$ & $C_{5,2}=Q_{5,2}$ & $C_{5,3}=Q_{4,3}$ & $C_{5,4}=Q_{5,4}$ & $C_{5,5}=Q_{1,5}$ \\
\hline$t=6$ & $C_{6,1}=Q_{6,1}$ & $C_{6,2}=Q_{5,2}$ & $C_{6,3}=Q_{4,3}$ & $C_{6,4}=Q_{5,4}$ & $C_{6,5}=Q_{6,5}$ \\
\hline$t=7$ & $C_{7,1}=Q_{7,1}$ & $C_{7,2}=Q_{7,2}$ & $C_{7,3}=Q_{7,3}$ & $C_{7,4}=Q_{5,4}$ & $C_{7,5}=Q_{6,5}$ \\
\hline$t=8$ & $C_{8,1}=Q_{8,1}$ & $C_{8,2}=Q_{7,2}$ & $C_{8,3}=Q_{7,3}$ & $C_{8,4}=Q_{5,4}$ & $C_{8,5}=Q_{6,5}$ \\
\hline$t=9$ & $C_{9,1}=Q_{9,1}$ & $C_{9,2}=Q_{9,2}$ & $C_{9,3}=Q_{7,3}$ & $C_{9,4}=Q_{9,4}$ & $C_{9,5}=Q_{6,5}$ \\
\hline$t=10$ & $C_{10,1}=Q_{10,1}$ & $C_{10,2}=Q_{9,2}$ & $C_{10,3}=Q_{10,3}$ & $C_{10,4}=Q_{9,4}$ & $C_{10,5}=Q_{6,5}$ \\
\hline
\end{tabular}

Note: This table shows how the constraint $C_{t, j}=\lambda_{j} Q_{t, j}+\left(1-\lambda_{j}\right) Q_{t-1, j}$ is updated in equation (1).

$1\left(A_{1, j}\right)$. After the first production year, the producer chooses to update his or her knowledge of soil $\mathrm{K}$ at the beginning of each period, following five soil test schedules $j$ defined as follows:

$$
\begin{gathered}
j=1, \quad \lambda=\left\{\begin{array}{ll}
1 & \text { if } t=1, \ldots, 10 \\
0 & \text { otherwise }
\end{array},\right. \\
j=2, \quad \lambda=\left\{\begin{array}{ll}
1 & \text { if } t=1,3,5,7,9 \\
0 & \text { otherwise }
\end{array},\right. \\
j=3, \quad \lambda=\left\{\begin{array}{ll}
1 & \text { if } t=1,4,7,10 \\
0 & \text { otherwise }
\end{array},\right. \\
j=4, \quad \lambda=\left\{\begin{array}{ll}
1 & \text { if } t=1,5,9 \\
0 & \text { otherwise }
\end{array},\right. \\
j=5, \quad \lambda=\left\{\begin{array}{ll}
1 & \text { if } t=1,6 \\
0 & \text { otherwise }
\end{array} .\right.
\end{gathered}
$$

When a producer did not test soil in a given year, the producer's knowledge of carryover $\mathrm{K}\left(C_{t, j}\right)$ was assumed to be the actual carryover $\mathrm{K}$ obtained from the most recent soil test $\left(Q_{t-1, j}\right)$. However, when a producer did soil test, the producer's knowledge of carryover $\mathrm{K}\left(C_{t, j}\right)$ was still assumed to be the actual carryover $\mathrm{K}$ obtained from the most recent soil test $\left(Q_{t, j}\right)$. Table 1 shows how the producer's knowledge of $\mathrm{K}$ carryover is updated with actual soil test information by temporal frequency. 
When maximizing NPV, the economic optimality principle of marginal value product (MVP) equals marginal factor cost (MFC) is complicated by intertemporal factors such as the time value of money (opportunity cost) and fertilizer carryover (Kennedy, 1986; Kennedy et al., 1973). Therefore, a dynamic optimization technique was required to determine optimal total $\mathrm{K}$ levels in each period when using soil test information. This study extends Kennedy's (1986) dynamic programing framework to determine optimal total available $\mathrm{K}$ levels in each period:

$$
V_{t, j}\left\{C_{t, j}\right\}=\max _{A_{t, j}}\left[N R_{t, j}+\delta V_{t+1, j}\left\{C_{t+1, j}\right\}\right]
$$

Subject to:

$$
\begin{aligned}
& A_{t, j}, C_{t, j} \geq 0 \\
& C_{t+1, j}=a_{0}+a_{1}\left(A_{t, j}+C_{t, j}\right) \\
& C_{t, j}=\lambda_{j} Q_{t, j}+\left(1-\lambda_{j}\right) Q_{t-1, j} \\
& V_{T+1, j}\left\{C_{T+1, j}\right\}=0 \\
& Q_{0}=\text { given, }
\end{aligned}
$$

where $V_{t, j}\left\{C_{t, j}\right\}$ is the present value of net returns (\$/ac.) from applying the profitmaximizing $\mathrm{K}$ application in year $t$; and $V_{T+1, j}\left\{C_{T+1, j}\right\}=0$ is the terminal condition stating that the producer does not receive any economic value from the available $\mathrm{K}$ remaining in the soil after the last period of the planning horizon because the producer will not be able to utilize these available soil $\mathrm{K}$ levels (Chiang, 1992).

The optimal single period applied K level was determined using Bellman's (1957) recursive equation. The optimality conditions were solved by differentiating equation (8) with respect to the decision variable $A_{t, j}$ as follows:

$$
\frac{\partial V_{t, j}}{\partial A_{t, j}}=\delta p_{t}^{c} \frac{\partial y_{t, j}}{\partial A_{t, j}}-p_{t}^{K}+\delta \frac{d V_{t+1, j}}{d C_{t+1, j}} a_{1}=0,
$$

which can be rearranged as

$$
\delta p_{t}^{c} \frac{\partial y_{t, j}}{\partial A_{t, j}}=p_{t}^{K}-\delta \frac{d V_{t+1, j}}{d C_{t+1, j}} a_{1} .
$$

Using the envelope theorem (Léonard and Van Long, 1992), differentiating equation (8) with respect to the state variable $C_{t, j}$ gives the following:

$$
\frac{\partial V_{t, j}}{\partial C_{t, j}}=\delta p_{t}^{c} \frac{\partial y_{t, j}}{\partial A_{t, j}}+\delta \frac{d V_{t+1, j}}{d C_{t+1, j}} a_{1} .
$$

Substituting equation (10) into equation (11) and simplifying gives

$$
\frac{\partial V_{t, j}}{\partial C_{t, j}}=p_{t}^{K},
$$


which indicates soil carryover at the beginning of year $t$ is valued at the price of $\mathrm{K}$ in year $t$. This result can be updated to year $t+1$ :

$$
\frac{\partial V_{t+1, j}}{\partial C_{t+1, j}}=p_{t+1}^{K},
$$

which can be substituted into equation (10) to obtain the optimality condition for single period $\mathrm{K}$ application rate when using soil test information:

$$
\delta p_{t}^{c} \frac{\partial y_{t, j}}{\partial A_{t, j}}=p_{t}^{K}-\delta p_{t+1}^{K} a_{1} .
$$

Equation (14) indicates the current period optimal total available K level occurs where the MVP (left-hand side of equation 14) was equal to the MFC less the discounted savings associated with $\mathrm{K}$ carried over to the next year (righthand side of equation 14).

\subsection{K Carryover Function}

Soil $\mathrm{K}$ carryover was estimated as a linear function of total $\mathrm{K}$ available (i.e., applied $\mathrm{K}$ and actual carryover $\mathrm{K}$ ), which is a commonly used functional form (Harper et al., 2012; Jomini et al., 1991; Lanzer and Paris, 1981; Segarra et al., 1989). Parameter estimates for the carryover function were obtained using the actual measured total $\mathrm{K}$ available. However, depending on the producer's temporal frequency of soil testing, the producer's knowledge of carryover $\mathrm{K}$ in the dynamic programming model was updated in each time period with the actual soil $\mathrm{K}$ level or the soil $\mathrm{K}$ level from the previous soil test. A year random effect was included in the intercept:

$$
C_{t+1, i}=a_{0}+a_{1}\left(A_{t, i}+Q_{t, i}\right)+\tau_{t}+u_{t, i},
$$

where $\tau_{t} \sim N\left(0, \sigma_{\tau}{ }^{2}\right)$ is a random effect capturing the variation in carryover levels across years, and $u_{t, i} \sim N\left(0, u_{\tau}{ }^{2}\right)$ is a random error term capturing the variation in carryover levels because of unobserved factors in plot $i$. The two error terms were assumed to be independent. The intercept, $a_{0}$, represents some constant amount of available $\mathrm{K}$ that remains in the soil over the planning horizon; the slope, $a_{1}$, is the proportion of total $\mathrm{K}$ from the current year readily available to the next crop estimated using observed carryover K. Soil K from previous applications accumulates into current-period soil $\mathrm{K}$ levels; thus, the only relevant soil K carryover level is for the current period for each of the schedules. Maximum likelihood parameter estimates for equation (15) were obtained using the MIXED procedure in SAS 9.3 (SAS Institute Inc., 2011).

\subsection{Yield Response Function}

The selection of a functional form to characterize cotton lint yield response to $\mathrm{K}$ is important for determining application rates that maximize NPV (AckelloOgutu, Paris, and Williams, 1985). Plateau-type response functions, such as the 
linear response plateau or quadratic plus plateau, have been suggested to be more appropriate for characterizing yield response to fertilizer than polynomial or other nonlinear specifications (Ackello-Ogutu, Paris, and Williams, 1985; Bullock and Bullock, 1994; Cerrato and Blackmer, 1990). Plateau-type functional forms assume yield responds to an input in a linear or polynomial manner until it reaches a plateau, beyond which the input no longer limits yield. Tembo et al. (2008) extended the linear response plateau by including a normally distributed random effect in the plateau to capture variation in the plateau from stochastic events such as insects, weather, and disease. The linear response stochastic plateau (LRSP) developed by Tembo et al. (2008) has been found to be more appropriate than similar deterministic functional forms to model yield response to nutrient applications for several crops and provide more accurate economically optimal nutrient rates (Biermacher et al., 2009; Boyer et al., 2013; Tumusiime et al., 2011). Furthermore, Harmon et al. (2016) found the LRSP to be more appropriate than a deterministic linear plateau function in the dynamic programming framework. Therefore, cotton yield response to $\mathrm{K}$ applied and actual measured soil $\mathrm{K}$ was estimated using the LRSP function:

$$
y_{t, i}=\min \left[\beta_{0}+\beta_{1}\left(A_{t, i}+Q_{t, i}\right), \mu+v_{t}\right]+w_{t}+\varepsilon_{t, i},
$$

where $\beta_{0}$ and $\beta_{1}$ are the yield response parameters estimated using observed yields; $\mu$ is the expected plateau yield parameter (lb./ac.); $v_{t} \sim N\left(0, \sigma_{v}{ }^{2}\right)$ is a normally distributed plateau random effect; $w_{t} \sim N\left(0, \sigma_{w}{ }^{2}\right)$ is the intercept random effect isolating variation in yields from year to year; and $\varepsilon_{t, i} \sim N\left(0, \sigma_{\varepsilon}{ }^{2}\right)$ is the random error term accounting for variation in yields from unexplained factors. Independence is assumed across the three random effects. Maximum likelihood parameter estimates for equation (16) were obtained using the NLMIXED procedure in SAS 9.3 (SAS Institute Inc., 2011).

To solve for the optimal applied $\mathrm{K}$ rate, the optimality condition (equation 14) was updated with the first-order condition for the LRSP yield response function with respect to applied $\mathrm{K}$, defined as

$$
\delta p_{t}^{c}\left[\beta_{1}(1-\Phi)\right]=p_{t}^{K}-\delta p_{t+1}^{K} a_{1}
$$

where $\Phi=\Phi\left\{\left[\beta_{0}+\beta_{1}\left(A_{t, j}+C_{t, j}\right)-\mu\right] / \sigma_{v}\right\}$ is the standard normal cumulative distribution function (Tembo et al., 2008). Equation (17) is rearranged to obtain the optimal $\mathrm{K}$ application rate for period $t$ :

$$
A_{t, j}^{*}=\frac{\left[\Phi^{-1}\left(1-\frac{p_{t}^{K}-\delta p_{t+1}^{K} a_{1}}{\delta p_{t}^{c} \beta_{1}}\right)\right] \sigma_{v}+\mu-\beta_{0}}{\beta_{1}}-C_{t, j},
$$

which can be simplified to

$$
A_{t, j}^{*}=\frac{z_{m} \sigma_{v}+\mu-\beta_{0}}{\beta_{1}}-C_{t, j},
$$


where $z_{m}$ is a standard normal $z$-score, ${ }^{1}$ and $m$ is the observed probability in the right-hand tail of the standard normal distribution (Tembo et al., 2008). Thus, the optimal application decision depends on the deviation from the expected plateau yield $\left(z_{m} \sigma_{v}\right)$, which is conditioned on the ratio of per unit $\mathrm{K}$ cost and cotton lint price (Tembo et al., 2008). Additionally, the optimal application rate will depend on the temporal frequency of soil testing and the accuracy of the producer's knowledge of their soil K levels. For the producer who soil tests in every year $(j=1)$, the producer's knowledge of carryover $\mathrm{K}$ is equal to the actual $\mathrm{K}$ carryover in each year. However, for a producer who soil tests every other year $(j=2)$, the producer's knowledge of carryover $\mathrm{K}$ is equal to the actual soil $\mathrm{K}$ levels in years when a soil test occurs, but the producer's knowledge of carryover $\mathrm{K}$ may be higher or lower than the actual $\mathrm{K}$ carryover level in periods when the producer does not update soil testing information. Therefore, the producer who updates soil $\mathrm{K}$ levels less frequently may over- or underapply $\mathrm{K}$ depending on the variability of soil K carryover levels between years. Given that yield responds to the amount of applied and carryover $\mathrm{K}$, the producer's decision of which soil testing schedule to follow will affect yield and the subsequent returns achieved in each period. The NPV for the different soil testing schedules indicates how often a producer needs to update his or her information on soil $\mathrm{K}$ to maximize NPV.

\subsection{Monte Carlo Simulation}

A Monte Carlo simulation was used to introduce uncertainty into the dynamic programming model. One thousand iterations of a 10 -year planning period were simulated to generate output distributions of NPV for each of the five scenarios. The prices of $\mathrm{K}$ and cotton lint yield, as well as the yield response and carryover coefficients, were assumed to be stochastic, providing an ex ante analysis of the NPV of returns to $\mathrm{K}$ for each scenario. Figure 1 summarizes the general process used to solve the dynamic programming model. Shaded boxes correspond with stochastic parameters in the model.

Uncertainty surrounding the prices of cotton lint and $\mathrm{K}$ were introduced into the model by bootstrapping the observed real average annual prices of cotton lint and $\mathrm{K}$ for each period of the 10 -year planning horizon. To introduce uncertainty in the expected yield response, the yield response coefficients were simulated as multivariate normal (MVN) random variables:

$$
\left[\begin{array}{c}
\beta_{0}^{*} \\
\beta_{1}^{*} \\
\mu^{*} \\
\sigma_{v}^{2 *}
\end{array}\right] \sim \operatorname{MVN}\left(\left[\begin{array}{c}
\beta_{0}^{*} \\
\beta_{1}^{*} \\
\mu \\
\sigma_{v}^{2}
\end{array}\right],\left[\begin{array}{llll}
\sigma_{\beta_{0}}^{2} & \rho_{\beta_{0}, \beta_{1}} \sigma_{\beta_{0}} \sigma_{\beta_{1}} & \rho_{\beta_{0}, \mu} \sigma_{\beta_{0}} \sigma_{\mu} & \rho_{\beta_{0}, \sigma_{v}^{2}} \sigma_{\beta_{0}} \sigma_{\sigma_{v}^{2}} \\
\rho_{\beta_{1}, \beta_{0}} \sigma_{\beta_{1}} \sigma_{\beta_{0}} & \sigma_{\beta_{1}}^{2} & \rho_{\beta_{1}, \mu} \sigma_{\beta_{1}} \sigma_{\mu} & \rho_{\beta_{1}, \sigma_{v}^{2}} \sigma_{\beta_{1}} \sigma_{\sigma_{v}^{2}} \\
\rho_{\mu, \beta_{0}} \sigma_{\mu} \sigma_{\beta_{0}} & \rho_{\mu, \beta_{1}} \sigma_{\mu} \sigma_{\beta_{1}} & \sigma_{\mu}^{2} & \rho_{\mu, \sigma_{v}^{2}} \sigma_{\mu} \sigma_{\sigma_{v}^{2}} \\
\rho_{\sigma_{v}^{2}, \beta_{0}} \sigma_{\sigma_{v}^{2}} \sigma_{\beta_{0}} & \rho_{\sigma_{v}^{2}, \beta_{1}} \sigma_{\sigma_{v}^{2}} \sigma_{\beta_{1}} & \rho_{\sigma_{v}^{2}, \mu} \sigma_{\sigma_{v}^{2}} \sigma_{\mu} & \sigma_{\sigma_{v}^{2}}^{2}
\end{array}\right]\right),
$$

1 Following Tembo et al. (2008), $z_{m}=\left(\beta_{0}+\beta_{1} \mathrm{~A}_{t, j}-\mu\right) / \sigma_{v}$, evaluated at $m=(1-\Phi)=$ $\left[\left(p_{t}^{k}-\delta p_{t+1}^{K} a_{1}\right) /\left(\delta p_{t}^{c} \beta_{1}\right)\right]$, which is the observed probability in the right-hand tail of the standard normal distribution. 


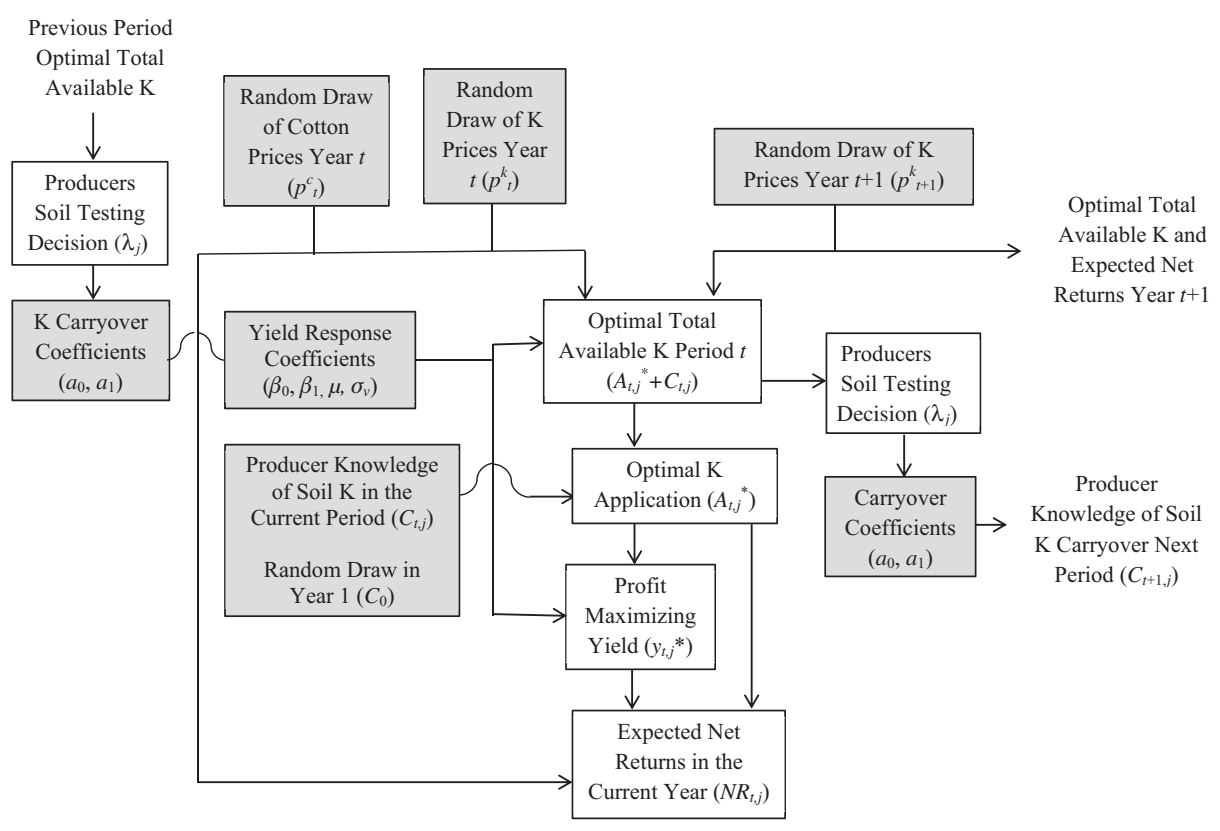

Figure 1. Flow Chart of the Dynamic Programming Model and Simulation Process of Solving for Optimal K Rates

where the mean of the distribution was a vector of the estimated coefficients for the yield response function (equation 16); the variance of the distribution was a four-by-four matrix of the robust covariance estimator of the parameter estimates, where $\rho$ is the correlation coefficient; and the asterisk denotes a randomly drawn coefficient for the simulation (Cuvaca et al., 2015). The preplanting carryover levels after the initial year were estimated by the linear carryover function (equation 15), where the carryover coefficients followed a MVN distribution:

$$
\left[\begin{array}{l}
a_{0}^{*} \\
a_{1}^{*}
\end{array}\right] \sim \operatorname{MVN}\left(\left[\begin{array}{l}
a_{0} \\
a_{1}
\end{array}\right],\left[\begin{array}{ll}
\sigma_{a_{0}}^{2} & \rho_{a_{0}, a_{1}} \sigma_{a_{0}} \sigma_{a_{1}} \\
\rho_{a_{1}, a_{0}} \sigma_{a_{1}} \sigma_{a_{0}} & \sigma_{a_{1}}^{2}
\end{array}\right]\right) .
$$

For each iteration, new coefficients and prices were randomly sampled to determine, ex ante, the total available K, yield, and NPV.

Uncertainty surrounding the initial carryover level $\left(Q_{0}\right)$ was introduced into the model by bootstrapping the observed carryover levels. In year 1, prices of $\mathrm{K}$ and cotton were randomly drawn along with parameter estimates for the carryover and yield response function. The producer was assumed to soil test in year 1 , so the preplanting carryover level was determined using the initial carryover level. The yield and carryover parameter estimates, prices of $\mathrm{K}$ and cotton, and the estimated preplanting $\mathrm{K}$ carryover level were substituted into equation (18) to obtain the optimal application rate in year 1. Subsequent yield 
and single period net returns were calculated at the optimal application rate and the carryover level. In time period 2, new prices of $\mathrm{K}$ and cotton were randomly drawn. After the first period of production, the producer's decision to soil test in each period was determined by the soil testing temporal frequency he or she follows. If the producer tested soil $\mathrm{K}$ levels, the optimal $\mathrm{K}$ rate was determined using the actual carryover $\mathrm{K}$ rate in time period 2 . If the producer did not soil test, the producer's knowledge of carryover K was used to determine the optimal $\mathrm{K}$ application rate. The subsequent yield and NPV were determined using the application rate and actual carryover levels, and the soil testing decision process was repeated for the remaining years of the planning period for each soil testing schedule. Therefore, after the first year of production, $\mathrm{K}$ applications, yield, and NPV for years $t=2, \ldots, 10$ were influenced by the temporal frequency with which producers updated soil test information.

For each scenario, output distributions were generated for the annual and 10-year average applied K, carryover K, lint yield, and NPV for each scenario. The Monte Carlo simulation was conducted using @Risk (Palisade Corporation, 2014). The expected NPVs of each scenario were compared to determine the soil testing temporal frequency that provided the greatest NPV of returns to K.

\section{Data}

Data on cotton yield response and soil $\mathrm{K}$ fertility levels were collected from a 9-year field study (2000 to 2008) conducted at the University of Tennessee, West Tennessee Research and Education Center at Jackson $\left(35.63^{\circ} \mathrm{N}, 88.85^{\circ}\right.$ W). The soil type was Loring-Calloway silt loam (thermic Oxyaquic Fragiudal and thermic Typic Fragiaqualf). The plots were not tilled. Each year, K fertilizer (muriate of potash, 0-0-60) was broadcast by hand to individual plots prior to planting at rates of $0,25,50,75,100,125$, and $149 \mathrm{lb}$./ac. of elemental K. These treatments were applied to the same plots each year, beginning 5 years prior to the start of the study (2000) through the last year (2008). Plots were arranged in a randomized complete block design, with five or six replications of the fertilizer treatments.

Cotton was planted between April 30 and May 15 of each year using a four-row John Deere MaxEmerge planter. From 2000 to 2002, the cultivar 'PM1218BG/RR' was planted on all plots. From 2003 to 2008, two contrasting cultivars were planted in a factorial arrangement relative to the K-fertility plots. The cultivars 'PM1218BG/RR' and DP555BG/RR' were planted from 2003 to 2005, the cultivars 'FM960BR' and DP555BG/RR' were planted from 2006 to 2007, and the cultivars 'ST455B2RF' and 'ST5327B2RF' were planted in $2008 .^{2}$ Plots were 30 by 12 feet, each containing four rows spaced 38 inches apart. Shortly before or after planting each year, nitrogen fertilizer (ammonium nitrate,

2 Analysis of variance indicated there was no difference in yield across cultivars. 
Table 2. Total Monthly Precipitation Levels for the Growing Season of Upland Cotton in Jackson, Tennessee, 2000-2008

\begin{tabular}{lrrrrrrrrrr}
\hline \hline & \multicolumn{7}{c}{ Precipitation Totals (inches) } \\
\cline { 2 - 10 } Month & 2000 & 2001 & 2002 & 2003 & 2004 & 2005 & 2006 & 2007 & 2008 & Average \\
\hline March & 3.93 & 2.81 & 13.00 & 3.56 & 2.50 & 4.10 & 1.77 & 1.15 & 9.75 & 4.83 \\
April & 5.22 & 2.48 & 1.10 & 2.34 & 9.08 & 8.54 & 5.42 & 3.25 & 8.23 & 5.07 \\
May & 3.52 & 4.87 & 5.90 & - & 6.23 & 0.36 & 3.60 & 0.86 & 6.86 & 4.02 \\
June & 3.99 & 4.82 & 2.45 & 6.06 & 2.90 & 6.87 & 4.94 & 2.71 & 2.81 & 4.17 \\
July & 2.46 & 4.71 & 0.85 & 2.42 & 4.74 & 5.46 & 2.12 & 1.76 & 6.28 & 3.42 \\
August & 2.92 & 4.65 & 5.35 & 3.43 & 4.93 & 7.27 & 3.53 & 0.77 & 2.55 & 3.93 \\
September & 3.27 & 2.28 & 13.09 & 2.79 & 0.69 & 3.95 & 2.89 & 6.28 & 0.79 & 4.00 \\
October & 0.86 & 7.37 & 6.41 & 4.16 & 7.99 & 0.14 & 2.62 & 8.97 & 3.15 & 4.63 \\
Total & 26.17 & 33.99 & 48.15 & 24.76 & 39.06 & 36.69 & 26.89 & 25.75 & 40.43 & 33.54 \\
\hline \hline
\end{tabular}

Source: National Oceanic and Atmospheric Administration, National Climatic Data Center (2016).

34-0-0) was uniformly drop-spread to all plots at a rate of $80 \mathrm{lb}$./ac. University of Tennessee Extension Service recommendations were followed for lime and phosphorus applications (Savoy and Joines, 2001). Supplemental irrigation was used during dry spells in all years except 2002 and 2003. Monthly growing season rainfall for Jackson, Tennessee, is summarized in Table 2 (National Oceanic and Atmospheric Administration, National Climatic Data Center, 2016). All other production practices followed the University of Tennessee Agricultural Extension Service (2001) guidelines for cotton production.

Seed cotton was harvested from the two interior rows of each plot twice each year using a modified John Deere 9930 spindle picker. First harvest occurred from September 7 to October 8, with a second harvest occurring 14 to 28 days later. Lint yields were calculated using seed cotton weights, gin turnouts, and plot areas harvested. Yield response functions were estimated using observed lint yields from 2000 to 2008. Average annual lint yields by K rate are displayed in Table 3. Yields may have increased over time because of improved biotechnology from different cultivars. Therefore, cotton lint yields were tested with a deterministic quadratic time response function (Just and Weninger, 1999). Similar to cotton yields in Oklahoma (Boyer, Brorsen, and Tumusiime, 2015), a time trend was not present.

Within 6 weeks after harvest in each year, soil samples were collected from all plots at the 0 - to 6-inch depth using the Mehlich I extraction method (Howard et al., 2001). The samples were tested at the University of Tennessee Soil and Forage Test Laboratory in Nashville, Tennessee. Preplanting soil test levels from 2001 to 2009 were used to estimate the carryover function. The average soil test level for the experiment was characterized by the medium soil fertility range (Savoy and Joines, 2001) (Table 2). Soil test levels were corrected for heteroskedasticity across years. 
Table 3. Average Annual Cotton Lint Yield and Postharvest $\mathrm{K}$ Carryover Level by $\mathrm{K}$ Application Rate in Jackson, Tennessee, 2000-2008

\begin{tabular}{lrrrrrrrrrr}
\hline \hline $\begin{array}{l}\text { K rate } \\
\text { (lb./ac.) }\end{array}$ & $2000^{\mathrm{a}}$ & 2001 & 2002 & 2003 & 2004 & 2005 & 2006 & 2007 & 2008 & Average \\
\hline \multicolumn{7}{c}{} & & \multicolumn{7}{c}{ Yield (lb./ac.) } \\
0 & 880 & 827 & 475 & 809 & 960 & 871 & 695 & 903 & 597 & 780 \\
25 & 1,092 & 1,209 & 756 & 1,208 & 1,519 & 1,305 & 1,242 & 1,312 & 1,300 & 1,216 \\
50 & 1,117 & 1,242 & 835 & 1,387 & 1,873 & 1,487 & 1,427 & 1,314 & 1,419 & 1,345 \\
75 & 1,191 & 1,368 & 1,003 & 1,403 & 1,812 & 1,384 & 1,408 & 1,274 & 1,595 & 1,382 \\
100 & 1,171 & 1,392 & 1,072 & 1,451 & 1,999 & 1,536 & 1,462 & 1,275 & 1,581 & 1,438 \\
124 & 1,173 & 1,366 & 1,069 & 1,370 & 1,857 & 1,390 & 1,310 & 1,129 & 1,447 & 1,346 \\
149 & 1,184 & 1,402 & 1,038 & 1,375 & 1,920 & 1,430 & 1,317 & 1,120 & 1,383 & 1,352 \\
& & & & Preplanting K Carryover Levels (lb./ac.) & & \\
0 & - & 119 & 110 & 139 & 98 & 88 & 104 & 93 & 102 & 104 \\
25 & - & 154 & 147 & 177 & 150 & 123 & 130 & 123 & 142 & 144 \\
50 & - & 178 & 186 & 204 & 219 & 177 & 195 & 188 & 222 & 196 \\
75 & - & 245 & 222 & 249 & 297 & 229 & 238 & 252 & 271 & 251 \\
100 & - & 325 & 270 & 301 & 395 & 307 & 337 & 298 & 318 & 319 \\
124 & - & 395 & 347 & 335 & 469 & 350 & 405 & 363 & 335 & 375 \\
149 & - & 459 & 521 & 376 & 528 & 440 & 458 & 467 & 491 & 468 \\
\hline \hline
\end{tabular}

a Preplanting K carryover levels were not measured for the year 2000.

Average annual cotton lint and elemental K prices (\$/lb.) from 1994 to 2013 were used to determine the $\mathrm{K}$ fertilization rates that maximized NPV over a 10-year planning horizon. The Federal Reserve implicit price deflator (Federal Reserve Bank of St. Louis, 2016) was used to adjust nominal prices to reflect real prices in 2013. From 1994 to 2013, real average annual cotton prices varied from $\$ 0.38$ to $\$ 1.07 / \mathrm{lb}$., and real average annual elemental $\mathrm{K}$ prices varied from $\$ 0.20$ to $\$ 0.91 /$ b. (U.S. Department of Agriculture, Economic Research Service, 2013, 2014). Real cotton and K prices were not correlated over time. The real cost of soil testing included the cost of obtaining the soil sample and the chemical analysis. The cost of obtaining the soil sample was $\$ 7.27 /$ ac. per year, which was based on the University of Tennessee Custom Rate Survey (Bowling, 2013). The cost of the chemical analysis was $\$ 0.70 /$ ac. per year, which assumes a producer soil tests on a 10-acre grid, following University of Tennessee recommendations for soil testing (Savoy and Joines, 2013). A 5\% discount rate was used to represent the opportunity cost of land in cotton production, similar to previous dynamic programming literature (Harper et al., 2012; Kennedy et al., 1973; Park et al., 2007; Segarra et al., 1989; Watkins, Lu, and Huang, 1998).

\section{Results}

\subsection{Yield Response and Carryover}

The parameter estimates for the yield response and carryover functions are presented in Table 4. The intercept of the LRSP function was insignificant and 
Table 4. Parameter Estimates for the Linear Response Stochastic Plateau Yield Response to Total Available K and the Linear Carryover Function

\begin{tabular}{lll}
\hline \hline Parameter $^{\mathrm{a}, \mathrm{b}}$ & Stochastic Plateau & Carryover $^{\mathrm{c}}$ \\
\hline Intercept $^{\mathrm{d}}\left(\beta_{0}, a_{0}\right)$ & -60.27 & $25.46^{* * *}$ \\
& $(90.69)$ & $(6.78)$ \\
Slope $^{\mathrm{d}}\left(\beta_{1}, a_{1}\right)$ & $7.95^{* * *}$ & $0.73^{* * *}$ \\
& $(0.54)$ & $(0.02)$ \\
Plateau yield $^{\mathrm{d}}(\mu)$ & $1,397.05^{* * *}$ & - \\
Plateau random effect $\left(\sigma_{v}^{2}\right)$ & $(14.36)$ & - \\
& $31,996^{* * *}$ & \\
Year random effect $\left(\sigma_{w}^{2}, \sigma_{\tau}^{2}\right)$ & $(4,172.66)$ & 235.71 \\
& $33,787^{* * *}$ & \\
Random error $\left(\sigma_{\epsilon}^{2}, \sigma_{u}^{2}\right)$ & $(5,197.98)$ & 2.74 \\
\hline \hline
\end{tabular}

${ }^{a}$ Single, double, and triple asterisks $\left({ }^{*},{ }^{* *},{ }^{* * *}\right)$ represent significance at the $10 \%, 5 \%$, and $1 \%$ levels, respectively.

${ }^{\mathrm{b}}$ Standard errors are in parentheses.

${ }^{\mathrm{c} C a r r y o v e r ~ d a t a ~ w e r e ~ c o r r e c t e d ~ f o r ~ h e t e r o s k e d a s t i c i t y . ~}$

${ }^{\mathrm{d}}$ Units are reported in $\mathrm{lb} . / \mathrm{ac}$.

negative, indicating that the intercept was not statistically different than zero. Total available $\mathrm{K}$ was always observed to be greater than zero (Table 3); thus, a negative yield would be outside the range of the data. Similarly, Watkins, Lu, and Huang (1998) and Stauber, Burt, and Linse (1975) found insignificant negative estimated intercepts in their yield response to nitrogen when carryover was considered. The remaining parameter estimates had the expected positive signs and were significant at the $1 \%$ level. Estimated yields from the LRSP function were plotted against observed yield response to total available K in Figure 2.

The estimated $\mathrm{K}$ carryover function had positive estimates for the intercept and slope $(P \leq 0.01)$. The intercept indicated that $25.46 \mathrm{lb}$. K/ac. of soil $\mathrm{K}$ did not come from the amount of total $\mathrm{K}$ in the previous year but remains available to the plant over the planning period (Lanzer and Paris, 1981). The estimated slope indicated that $73 \%$ of the total $\mathrm{K}$ available in the current period $(t)$ will be carried over to the next period $(t+1)$. The carryover coefficient was similar to Harper et al.'s (2012) estimated K carryover coefficient of 0.72 .

\subsection{Simulation}

Monte Carlo simulation results for the annual and 10 -year average $\mathrm{K}$ application, $\mathrm{K}$ carryover, and yield are presented in Table 5. The 10-year average profitmaximizing $\mathrm{K}$ application rates for all temporal frequencies of soil testing varied from 29 to $31 \mathrm{lb}$./ac. per year. However, the range of optimal $\mathrm{K}$ application rates across the years varied by temporal frequency of soil testing. The optimal $\mathrm{K}$ application in years when a producer did not update his or her soil $\mathrm{K}$ information 


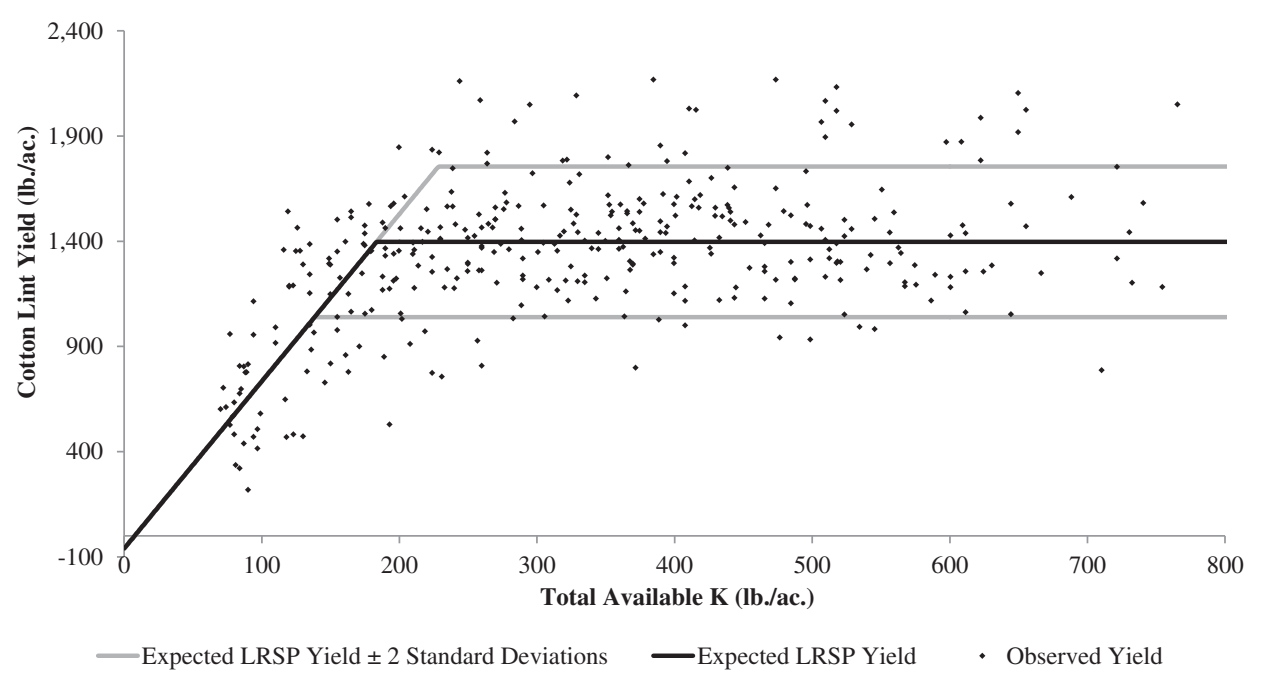

Figure 2. Visualizing the Fit of the Linear Response Stochastic Plateau (LRSP) Functional Form on the Observed Cotton Lint Yield Data

with a soil test was lower than the optimal $\mathrm{K}$ application rate when a producer did update his or her information on soil $\mathrm{K}$ carryover. These lower applications were offset by applying a higher rate in years when soil testing information was updated to correct for $\mathrm{K}$ deficiencies in soil carryover levels. For example, in year 2 , the producer that soil tested every year applied a higher $\mathrm{K}$ rate to maximize NPV than the producer that soil tested every other year. However, the optimal K application rate for the producer that soil tested every other year was higher in year 3 than the optimal $\mathrm{K}$ rate for the producer that soil tested every year, which was necessary to rebuild total available K levels to maximize NPV. The longer the producer waited to update his or her information on soil $\mathrm{K}$ carryover with a soil test, the greater the range of optimal $\mathrm{K}$ application rate increased.

The 10-year average optimal K carryover levels were $204 \mathrm{lb}$./ac. per year when a producer updated soil testing information annually. However, when a producer soil tested every other year and every third year, average soil carryover levels were reduced by $2 \mathrm{lb}$./ac. per year, and average carryover levels were 3 and $4 \mathrm{lb}$./ac. per year lower than annual soil testing when a producer waited 4 and 5 years to update soil testing information, respectively. However, as temporal frequency of soil testing decreased, the lower bound of the range of annual $\mathrm{K}$ carryover level decreased. For instance, when a producer waited 5 years to soil test, the carryover K level dropped from $238 \mathrm{lb}$./ac. at the beginning of period 1 to 159 $\mathrm{lb}$./ac. when the producer updated soil test information at the beginning of period 6 , which was $26 \mathrm{lb}$./ac. lower than the $\mathrm{K}$ carryover level for a producer who soil tests annually. To correct this deficiency, the producer applied a higher rate of $\mathrm{K}$, relative to annual soil testing, to increase the soil $\mathrm{K}$ levels. This result shows that 
Table 5. Monte Carlo Simulation Results for the Optimal K Application Rate, Potassium Carryover, and Yield by Simulation Year for a 10-Period Planning Horizon

\begin{tabular}{|c|c|c|c|c|c|}
\hline \multirow[b]{2}{*}{ Value } & \multicolumn{5}{|c|}{ Temporal Frequency } \\
\hline & $\begin{array}{l}\text { Every } \\
\text { Year }\end{array}$ & $\begin{array}{l}\text { Every Second } \\
\text { Year }\end{array}$ & $\begin{array}{l}\text { Every Third } \\
\text { Year }\end{array}$ & $\begin{array}{l}\text { Every Fourth } \\
\text { Year }\end{array}$ & $\begin{array}{l}\text { Every Fifth } \\
\text { Year }\end{array}$ \\
\hline & \multicolumn{5}{|c|}{ K Application (lb./ac.) } \\
\hline Period 1 & 28 & 28 & 28 & 28 & 28 \\
\hline Period 2 & 20 & 10 & 10 & 10 & 10 \\
\hline Period 3 & 27 & 33 & 21 & 21 & 21 \\
\hline Period 4 & 31 & 20 & 41 & 13 & 13 \\
\hline Period 5 & 33 & 42 & 28 & 54 & 18 \\
\hline Period 6 & 34 & 29 & 36 & 27 & 63 \\
\hline Period 7 & 35 & 38 & 36 & 43 & 29 \\
\hline Period 8 & 34 & 34 & 37 & 33 & 52 \\
\hline Period 9 & 34 & 36 & 36 & 35 & 35 \\
\hline Period 10 & 27 & 27 & 26 & 26 & 39 \\
\hline \multirow[t]{2}{*}{ Average } & 30 & 30 & 30 & 29 & 31 \\
\hline & \multicolumn{5}{|c|}{ K Carryover (lb./ac.) } \\
\hline Period 0 & 293 & 293 & 293 & 293 & 293 \\
\hline Period 1 & 238 & 238 & 238 & 238 & 238 \\
\hline Period 2 & 218 & 218 & 218 & 218 & 218 \\
\hline Period 3 & 199 & 191 & 191 & 191 & 191 \\
\hline Period 4 & 189 & 188 & 180 & 180 & 180 \\
\hline Period 5 & 185 & 176 & 186 & 166 & 166 \\
\hline Period 6 & 185 & 184 & 181 & 185 & 159 \\
\hline Period 7 & 185 & 180 & 183 & 179 & 186 \\
\hline Period 8 & 184 & 184 & 184 & 187 & 182 \\
\hline Period 9 & 184 & 183 & 186 & 185 & 195 \\
\hline Period 10 & 184 & 184 & 186 & 185 & 193 \\
\hline \multirow[t]{2}{*}{ Average } & 204 & 202 & 202 & 201 & 200 \\
\hline & \multicolumn{5}{|c|}{ Cotton Lint Yield (lb./ac.) } \\
\hline Period 1 & 1,389 & 1,389 & 1,389 & 1,389 & 1,389 \\
\hline Period 2 & 1,388 & 1,378 & 1,378 & 1,378 & 1,378 \\
\hline Period 3 & 1,386 & 1,383 & 1,347 & 1,347 & 1,347 \\
\hline Period 4 & 1,383 & 1,371 & 1,382 & 1,285 & 1,285 \\
\hline Period 5 & 1,383 & 1,379 & 1,375 & 1,380 & 1,212 \\
\hline Period 6 & 1,383 & 1,376 & 1,369 & 1,376 & 1,380 \\
\hline Period 7 & 1,382 & 1,380 & 1,382 & 1,376 & 1,378 \\
\hline Period 8 & 1,382 & 1,380 & 1,382 & 1,372 & 1,386 \\
\hline Period 9 & 1,382 & 1,381 & 1,380 & 1,383 & 1,383 \\
\hline Period 10 & 1,379 & 1,377 & 1,381 & 1,376 & 1,375 \\
\hline Average & 1,384 & 1,379 & 1,376 & 1,366 & 1,352 \\
\hline
\end{tabular}

when a producer does not know or use soil $\mathrm{K}$ carryover information in managing $\mathrm{K}$ applications, the optimal strategy was to draw down soil $\mathrm{K}$ levels. In turn, the drawing down of soil $\mathrm{K}$ levels requires producers to apply higher rates of $\mathrm{K}$ in years that soil test information is updated. This finding also resembles what 
southeastern cotton producers experienced in the late 1980s and early 1990s with K deficiencies (Maples, Thompson, and Varvil, 1988; Mullins, Burmester, and Reeves, 1997), which reiterates the importance of soil testing for $\mathrm{K}$ levels in cotton production in the southeastern United States.

The 10-year average $\mathrm{K}$ carryover levels reported in this study would be classified in the medium soil fertility range for each soil testing schedule according to the University of Tennessee Extension Service guidelines (Savoy and Joines, 2001). However, the University of Tennessee Extension Service recommends K application rates of $90 \mathrm{lb}$./ac. for medium testing soils in cotton production, which are higher than the optimal rates reported in this study. Moreover, Harper et al. (2012) reported optimal total K levels of $516 \mathrm{lb}$./ac., which is higher than the optimal total K levels reported in this study. However, Harper et al. (2012) used data from a shorter time series on a different soil type and a different yield response function than used in this study, which might explain the differences in results. Our results suggest that recommended $\mathrm{K}$ application rates in cotton production based on soil test levels could be decreased.

Annual soil testing produced the highest 10 -year average yield of $1,384 \mathrm{lb} . / \mathrm{ac}$. per year, and the 10-year average lint yields decreased as the producer's temporal frequency of soil testing decreased. By waiting until every fifth year to soil test, the producer decreased his or her yield by $32 \mathrm{lb}$./ac. per year relative to the producer that soil tests annually. The longer a producer waited to update soil testing information, the lower the annual yields decreased, which might be attributed to the deficient soil carryover levels limiting yield.

\subsection{Optimal Temporal Frequency}

The expected NPV increased as temporal frequency increased from soil testing every fifth year $(\$ 7,436 /$ ac. $)$ to soil testing every other year $(\$ 7,580 /$ ac. $)$ (Figure 3). This indicates that the additional information on soil $\mathrm{K}$ carryover had a greater value than the cost of soil testing. The expected NPV increased $\$ 83 /$ ac. when a producer went from soil testing every 5 years to every 4 years, $\$ 48 /$ ac. when a producer went from soil testing every 4 years to every 3 years, and $\$ 13 /$ ac. when a producer went from soil testing every 3 years to every other year (Figure 3). Thus, the findings further indicate that the value of soil testing increased at a decreasing rate when the temporal frequency of soil testing increased. Annual soil testing provided the producer with the most accurate knowledge of soil $\mathrm{K}$ carryover variability over time. However, results from this study suggest that the additional value from having the most accurate information on soil $\mathrm{K}$ carryover was less than the cost of soil testing to gather that information. When a producer soil tested annually, the expected NPV decreased by $\$ 12 /$ ac. from soil testing every other year (Figure 3).

Pairwise comparisons were made between the distributions of simulated NPVs for all temporal frequencies of soil testing. The NPV of soil testing every other year was statistically different than the NPVs from soil testing every fourth 


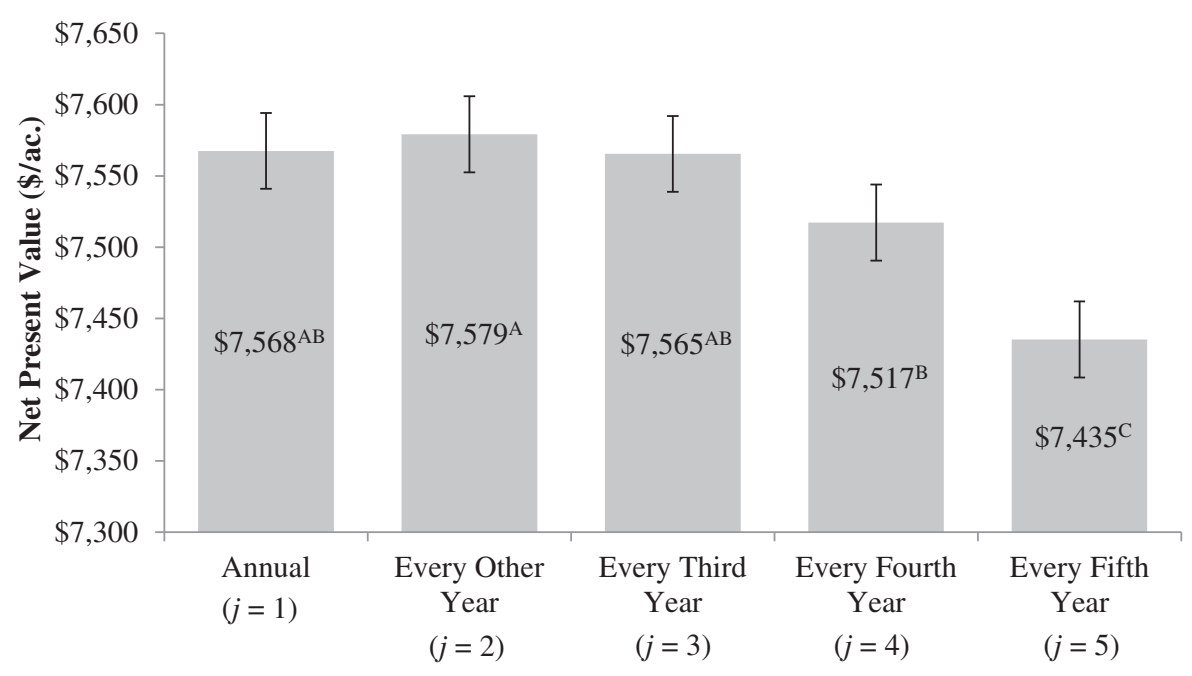

Soil Testing Temporal Frequency

Figure 3. Net Present Value from Applying Optimal K Rates over a 10-Year Planning Period for Five Soil Testing Schedules (different letters indicate a significant difference at the 0.05 level; least significant difference $=58$ )

$(P$ value $=0.08)$ and fifth year $(P$ value $=<0.0001)$ at the 0.05 level. However, the NPV of soil testing every other year was not statistically different than the NPVs from soil testing annually and every third year. Although producers who use soil testing information to manage $\mathrm{K}$ in cotton production can maximize their expected NPV by updating soil testing information every other year, the optimum soil testing temporal frequency may be found soil testing annually to every 3 years. ${ }^{3}$ The conclusion about optimal temporal frequency of soil testing was supported by what Lambert et al. (2014) found in their survey of cotton producers in the southern United States.

\section{Conclusion}

The objective of this study was to determine the temporal frequency of soil testing for $\mathrm{K}$ that maximized NPV of returns to $\mathrm{K}$ in cotton production. Cotton lint yield and soil testing data were obtained from a 9-year experiment in Jackson, Tennessee. Cotton lint yield was characterized by an LRSP yield response function, and soil testing information was characterized by a linear carryover function. The producer's objective was to choose the temporal frequency of soil testing and the subsequent annual $\mathrm{K}$ application rates that maximized his or her

3 As suggested by a reviewer, mean-variance criteria and stochastic dominance were used to find that the optimal decision for a risk-averse producer is to soil test every other year. 
NPV of returns to K over a 10-year planning period. Kennedy's (1986) dynamic programming framework was applied, and a Monte Carlo simulation was used to introduce uncertainty into the model.

Previous studies that investigate optimal nutrient application to maximize NPV assume that producers soil test on an annual basis; however, this assumption does not appear to follow producer practices (Lambert et al., 2014) or extension recommendations in the Southeast (Kissel and Sonon, 2011; Mylavarapu, 1997; Savoy and Joines, 2013). This study expands previous literature by incorporating the temporal frequency of soil testing into a dynamic programming model, and results will assist producers in making better-informed decisions regarding their use of soil testing as a tool to manage $\mathrm{K}$ in cotton production.

On average over the 10 -year production horizon, the profit-maximizing $\mathrm{K}$ application rates for all temporal frequencies of soil testing varied slightly from 29 to $31 \mathrm{lb}$./ac. per year. The longer producers waited to update their information on soil $\mathrm{K}$ carryover with a soil test, the greater the range of optimal $\mathrm{K}$ application rate increased. As producers decreased their temporal frequency of soil testing, the lower bounds of the carryover levels and yields decreased because of yieldlimiting levels of K. The expected NPV increased at a decreasing rate as temporal frequency increased from soil testing every fifth year to soil testing every other year, indicating that the value of the additional information from soil testing was greater than the cost of soil testing. However, the expected NPV decreased when producers increased their temporal frequency from every other year to annually; thus, the additional value from having the most accurate information on soil $\mathrm{K}$ carryover was less than the cost of soil testing to gather that information. The findings of this study are limited to the production region and soil type of the experiment. Production practices, weather, and soil type may produce an optimal soil testing temporal frequency that differs from the results of this study. Further research is needed on the optimal temporal frequency in other cotton-producing regions of the United States.

This study used an LRSP functional form assuming the expected plateau yield is normally distributed, but nonnormality in the expected plateau yield could increase or decrease the optimal $\mathrm{K}$ rates (Boyer, Brorsen, and Tumusiime, 2015). Nonnormality in the expected plateau yield may give producers an incentive to update information more frequently to sustain higher total $\mathrm{K}$ levels. Future research could investigate if skewness in the distribution of expected plateau lint yields has an impact on the optimal temporal frequency of soil testing or optimal $\mathrm{K}$ application rates for cotton.

\section{References}

Ackello-Ogutu, C., Q. Paris, and W.A. Williams. "Testing a Von Liebig Crop Response Function against Polynomial Specifications." American Journal of Agricultural Economics 67(November 1985):873-80. 
Bellman, R.E. Dynamic Programming. Princeton, NJ: Princeton University Press, 1957.

Biermacher, J.T., B.W. Brorsen, F.M. Epplin, J.B. Solie, and W.R. Raun. "The Economic Potential of Precision Nitrogen Application with Wheat Based on Plant Sensing." Agricultural Economics 40(July 2009):397-407.

Bowling, B. Custom Rates Survey, 2013. Knoxville: Department of Agricultural and Resource Economics, University of Tennessee, 2013. Internet site: http://economics.ag.utk.edu/ extension/pubs/CustomRates2013-rev.pdf (Accessed January 27, 2016).

Boyer, C.N., B.W. Brorsen, and E. Tumusiime. "Modeling Skewness with the Linear Stochastic Plateau Model to Determine Optimal Nitrogen Rates." Agricultural Economics 46(January 2015):1-10.

Boyer, C.N., J.A. Larson, R.K. Roberts, A.T. McClure, D.D. Tyler, and V. Zhou. 2013. "Stochastic Corn Yield Response Functions to Nitrogen for Corn after Corn, Corn after Cotton, and Corn after Soybeans." Journal of Agricultural and Applied Economics. 45(November 2013):669-81.

Bullock, D.G., and D.S. Bullock. "Quadratic and Quadratic-Plus-Plateau Models for Predicting Optimal Nitrogen Rate of Corn: A Comparison.” Agronomy Journal 86(January 1994):191-95.

Cerrato, M.E., and A.M. Blackmer. "Comparison of Models for Describing Corn Yield Response to Nitrogen Fertilizer.” Agronomy Journal 82(January 1990):138-43.

Chiang, A.C. Elements of Dynamic Optimization. New York: McGraw Hill, 1992.

Cuvaca, I.B., D.M. Lambert, F.R. Walker, M. Marake, and N.S. Eash. "Economically Optimal N Fertilizer Rates for Maize Produced on Vertisol and Inceptisol Soils under No-Till Management: A Case Study in Maphutseng Lesotho." International Journal of Plant and Soil Science 8(July 2015):1-12.

Essington, M.E., D.D. Howard, H.J. Savoy, and G.M. Lessman. "Potassium Fertilization of Cotton Produced on Loess-Derived Soils." Better Crops 86,4(2002):13-15.

Federal Reserve Bank of St. Louis. "Gross Domestic Product: Implicit Price Deflator (GDPDEF).” 2016. Internet site: http://research.stlouisfed.org/fred2/series/GDPDEF/ downloaddata (Accessed January 11, 2016).

Fuller, W.A. "Stochastic Fertilizer Production Functions for Continuous Corn." American Journal of Agricultural Economics 47(February 1965):105-19.

Harmon, X., C.N. Boyer, D.M. Lambert, J.A. Larson, and C.O. Gwathmey. "Comparing the Value of Soil Test Information Using Deterministic and Stochastic Yield Response Plateau Functions." Journal of Agricultural and Resource Economics 41,2(2016):30723.

Harper, D.C., D.M. Lambert, J.A. Larson, and C.O. Gwathmey. "Potassium Carryover Dynamics and Optimal Application Policies in Cotton Production." Agricultural Systems 106(December 2012):84-93.

Heady, E.O., and J.L. Dillon. Agricultural Production Functions. Ames: Iowa State University Press, 1961.

Howard, D.D., M.E. Essington, R.M. Hayes, and W.M. Percell. "Potassium Fertilization of Conventional- and No-Till Cotton.” Journal of Cotton Science 5,4(2001):197-205.

Howard, D.D., C.O. Gwathmey, R.K. Roberts, and G.M. Lessman. "Potassium Fertilization of Cotton Produced on a Low K Soil with Contrasting Tillage Systems.” Journal of Production Agriculture 11(January 1998):74-79.

Jomini, P.A., R.D. Deuson, J. Lowenberg-DeBoer, and A. Bationo. "Modelling Stochastic Crop Response to Fertilisation when Carry-Over Matters." Agricultural Economics 6(December 1991):97-113. 
Just, R.E., and Q. Weninger. “Are Crop Yields Normally Distributed?” American Journal of Agricultural Economics 81(May 1999):287-304.

Kennedy, J.O.S. Dynamic Programming: Applications to Agriculture and Natural Resources. London: Elsevier Applied Science, 1986.

Kennedy, J.O.S, I.F. Whan, R. Jackson, and J.L. Dillon. "Optimal Fertilizer Carryover and Crop Recycling Policies for a Tropical Grain Crop.” American Journal of Agricultural Economics 17(August 1973):104-13.

Kissel, D.E., and L. Sonon. Soil Test Handbook for Georgia. Athens: University of Georgia Cooperative Extension, 2011.

Lambert, D.M., B.C. English, D.C. Harper, S.L. Larkin, J.A. Larson, D.F. Mooney, R.K. Roberts, M. Velandia, and J.M. Reeves. "Adoption and Frequency of Precision Soil Testing in Cotton Production." Journal of Agricultural and Resource Economics 39(April 2014):106-23.

Lambert, D.M., J. Lowenberg-DeBoer, and G. Malzer. "Managing Phosphorus Soil Dynamics over Space and Time." Agricultural Economics 37(July 2007):43-53.

Lanzer, E.A., and Q. Paris. "A New Analytical Framework for the Fertilization Problem." American Journal of Agricultural Economics 63(February 1981):93-103.

Léonard, D., and N. Van Long. Optimal Control Theory and Static Optimization in Economics. Cambridge, UK: Cambridge University Press, 1992.

Maples, R.L., W.R. Thompson, Jr., and J. Varvil. "Potassium Deficiency in Cotton Takes on a New Look." Better Crops 73,1(1988):6-9.

Mehlich, A. Determination of $\mathrm{P}, \mathrm{Ca}, \mathrm{Mg}, \mathrm{K}, \mathrm{Na}$ and NH4. Raleigh, NC: North Carolina Department of Agriculture, Soil Testing Division Publication No. 1-53, 1953.

Mullins, G.L., C.H. Burmester, and D.W. Reeves. "Cotton Response to In-Row Subsoiling and Potassium Fertilizer Placement in Alabama." Soil and Tillage Research 40(January 1997):145-54.

Mullins, G.L., G.J. Schwab, and C.H. Burmester. "Cotton Response to Surface Applications of Potassium Fertilizer: A 10-Year Summary.” Journal of Production Agriculture 12(October 1999):434-40.

Mylavarapu, R.S. Soil Sampling for Precision Farming. Clemson, SC: Clemson University Cooperative Extension Service, Publication No. IL 63, 1997.

National Oceanic and Atmospheric Administration, National Climatic Data Center. “Climate Data Online Search.” Internet site: http://www.ncdc.noaa.gov/cdo-web/search (Accessed January 11, 2016).

Palisade Corporation. @ Risk. Ver. 6. Ithaca, NY: Palisade Corporation, 2014.

Park, S.C., A. Stocker, J.A. Hattey, and J.C. Turner. "Long-Term Profitability of Animal Manure Using Optimal Nitrogen Application Rate." Paper presented at the Southern Agricultural Economics Association Annual Meeting, Mobile, Alabama, February 4-7, 2007.

SAS Institute Inc. SAS/STAT 9.3 User's Guide. Cary, NC: SAS Institute Inc., 2011. Internet site: http://support.sas.com/documentation/cdl/en/statug/63962/HTML/default/viewer. htm\#titlepage.htm (Accessed January 11, 2016).

Savoy, H.J., Jr., and D. Joines. "Chapter 2: Agronomic Crops." Lime and Fertilizer Recommendations for the Various Crops of Tennessee. Knoxville: Agricultural Extension Service, University of Tennessee, Publication No. BEES Info 100, 2001, pp. $1-8$. 
Schnitkey, G.D., J.W. Hopkins, and L.G. Tweeten. “An Economic Evaluation of Precision Fertilizer Applications on Corn-Soybean Fields." Proceedings of the Third International Conference on Precision Agriculture, Minneapolis, Minnesota, June 23-26, 1996. Madison, WI: American Society of Agronomy, 1996, pp. 978-80.

Segarra, E., E.D. Ethridge, C.R. Deussen, and A.B. Onken. "Nitrogen Carry-Over Impacts in Irrigated Cotton Production, Southern High Plains of Texas." Western Journal of Agricultural Economics 14(December 1989):300-309.

Stauber, M.S., O.R. Burt, and F. Linse. "An Economic Evaluation of Nitrogen Fertilization of Grasses When Carry-Over Is Significant.” American Journal of Agricultural Economics 57(August 1975):463-71.

Tembo, G., B.W. Brorsen, F.M. Epplin, and E. Tostão. “Crop Input Response Functions with Stochastic Plateaus.” American Journal of Agricultural Economics 90(May 2008):42434.

Tumusiime, E., B.W. Brorsen, J. Mosali, J. Johnson, J. Locke, and J.T. Biermacher. "Determining Optimal Levels of Nitrogen Fertilizer Using Random Parameter Models.” Journal of Agricultural and Applied Economics 43(November 2011):541-52.

University of Tennessee Agricultural Extension Service. Cotton Production in Tennessee. Knoxville: University of Tennessee Agricultural Extension Service, Publication No. PB1514, 2001.

U.S. Department of Agriculture, Economic Research Service. “Table 7. Average U.S. Farm Prices of Selected Fertilizers, 1960-2013.” 2013. Internet site: https://www.ers.usda. gov/webdocs/DataFiles/Fertilizer_Use_and_Price_17978/fertilizeruse.xls?v=41467 (Accessed January 11, 2016).

—. "Table 11. U.S. Upland Cotton Farm, Spot, and Mill Prices, 1970/71-2013/14." 2014. Internet site: http://usda.mannlib.cornell.edu/usda/ers/89004/ (Accessed January 11, 2016).

Walworth, J.L. Soil Sampling and Analysis. Tucson: University of Arizona Cooperative Extension, Publication No. AZ1412, 2011.

Watkins, B., Y. Lu, and W. Huang. "Economic and Environmental Feasibility of Variable Rate Nitrogen Fertilizer Application with Carry-Over Effects." Journal of Agricultural and Resource Economics 23(December 1998):401-26.

Zhou, X., B.C. English, C.N. Boyer, R.K. Roberts, J.A. Larson, D.M. Lambert, M. Velandia, et al. Precision Farming by Cotton Producers in Fourteen Southern States: Results from the 2013 Southern Cotton Farm Survey. Knoxville: Department of Agricultural and Resource Economics, University of Tennessee, Research Series 15-001, 2015. 